\title{
Risk of venous thromboembolism during and after hospitalisation in patients with inflammatory bowel disease activity.
}

Running title: Timeliness of thromboprophylaxis in inflammatory bowel disease

Thomas P C Chu (1)

Matthew J Grainge (1)

Timothy R Card $(1,2)$

(1) Division of Epidemiology and Public Health, University of Nottingham, Nottingham, United Kingdom.

(2) Nottingham Digestive Diseases Centre Biomedical Research Unit, University of Nottingham, Nottingham, United Kingdom.

Correspondence: Thomas P C Chu, thomas.chu@nottingham.ac.uk

Division of Epidemiology and Public Health, Clinical Sciences Building, Nottingham City Hospital, University of Nottingham, Nottingham NG5 1PB. Tel: 01158231346

Main text (introduction to conclusions): 3,692 words. 


\section{Acknowledgements}

This study was made possible by a grant from Crohn's and Colitis UK. This work uses data provided by patients and collected by the National Health Service in the United Kingdom as part of their care and support.

Ethical approval for the use of data from Clinical Practice Research Datalink (formerly General Practice Research Database) in this study has been given by their Independent Scientific Advisory Committee (reference number 10_147). 


\section{SUMMARY}

\section{Background}

Inflammatory bowel disease (IBD) increases the risk of venous thromboembolism.

\section{Aim}

To determine when patients are at high risk of thromboembolic events, including after major surgery, and to guide timing of thromboprophylaxis.

\section{Methods}

Each inflammatory bowel disease patient from Clinical Practice Research Datalink, linked with Hospital Episode Statistics, was matched to up to five non-IBD patients in this cohort study. We examined their risk of thromboembolism in hospital and within six weeks after leaving hospital, with or without undergoing major surgery, and while ambulant. Hazard ratios were estimated using Cox regression, with adjustment for age, sex, body mass index, smoking and history of malignancy or thromboembolism.

\section{Results}

Overall 23,046 inflammatory bowel disease patients had a thromboembolic risk 1.74 times $(95 \% \mathrm{Cl}=1.55-1.96)$ higher than 106,795 non-IBD patients. Among ambulant patients, the thromboembolic risk was raised during acute (hazard ratio $=3.94,2.79$ $5.57)$ or chronic disease activity $(3.97,2.90-5.45)$ but their absolute risk remained below 5/1000 person-years. The hazard ratio for thromboembolism among in-patients 
not undergoing major surgery was 1.13 (0.63-2.02), compared to 2.43 (1.20-4.92) among surgical patients, with a near doubling of absolute risk associated with surgery (59.5/1000 person-years, compared with 31.1 without surgery). The absolute risk remained elevated within six weeks after leaving hospital (18.6/1000 personyears in inflammatory bowel disease patients after surgery).

\section{Conclusions}

Inflammatory bowel disease patients are at an increased risk of venous thromboembolism. Absolute risks are raised during active disease, when in hospital, and after leaving hospital following major surgery.

MeSH keywords: inflammatory bowel diseases, embolism and thrombosis, hospitalization, risk factors 


\section{INTRODUCTION}

Venous thromboembolism is a recognised complication of inflammatory bowel diseases (IBD).[1-3] It is associated with morbidity and mortality that are potentially avoidable with prophylaxis.[4] Thromboprophylaxis is not free of risk, cost or discomfort.

It is recognised that prophylaxis is justified by the size of thromboembolic risk among hospitalised inflammatory bowel disease patients, which leads to widespread acceptance that this should be routine.[5-8] We demonstrated that the risk of venous thromboembolism is also increased in ambulant inflammatory bowel disease patients, and the risk is higher in periods of bowel inflammation. [9] Our work did not demonstrate any additional period in which prophylaxis may be justified.

However, we were unable to elucidate the precise time periods when inflammatory bowel disease patients were at high risk of thromboembolic events due to limitations of the data, and we had to estimate the dates of hospital admission and discharge from general practice records.[9] We have since been able to obtain primary care records (Clinical Practice Research Datalink), linked to hospital records (Hospital Episode Statistics), and this enabled us to re-examine this issue using methodology from other studies investigating the association between venous thromboembolism and diseases using linked data.[10-12] Over the same period, it has become standard practice to extend thromboprophylaxis in patients undergoing major surgery for abdominal or pelvic cancers to up to 28 days after surgery.[13] We have therefore revisited the question of when inflammatory bowel disease patients are at an increased risk of thromboembolic events, defining admission and surgery dates using 
hospital records, and have also examined the period after leaving hospital when the effect of extended prophylaxis may occur.

\section{MATERIALS and METHODS}

\section{Data sources}

We identified a cohort of inflammatory bowel disease patients with a diagnosis of Crohn's disease, ulcerative colitis or indeterminate colitis recorded in Clinical Practice Research Datalink (previously known as the General Practice Research Database) consultation records between January 1987 and January 2011. We obtained linked records from Hospital Episode Statistics on in-patient stays between 1st April 1997 and 31st October 2010 and linked death records between 1st January 1998 and 10th January 2012 from the Office for National Statistics.

Clinical Practice Research Datalink (CPRD) is one of the world's largest databases of longitudinal primary care records. Over 600 practices, covering around $7 \%$ of the UK population, have been contributing data on primary care events such as consultations, symptoms and diagnoses, investigations and prescriptions. CPRD audits data from each practice and assigns an "up-to-standard" date, after which records are judged to be of acceptable standard for research. A primary care practice is designated as "up-to-standard" when the quality of the data it contributes meet the minimum quality criteria. Patient records after the "up-to-standard" date should not contain any significant gaps in their data and the recording of deaths or when patients left a practice is accurate.[14] These data are linked for a subset of practices to other data sources allowing enrichment of the data. The quality of data on 
inflammatory bowel disease and diagnoses of venous thromboembolism has also been validated externally.[10,15,16]

Hospital Episode Statistics (HES) contains routine records on clinical care (e.g. date of beginning and end of each episode, main and other diagnoses, surgical procedures, etc.) of in-patient stays at National Health Service hospitals in England. [17] Dates and the nature of clinical care received by each patient are recorded in medical notes by the medical team and coded at the end of each episode to become part of the data. The HES data quality team publish data quality reports with each release.[18]

\section{Patients}

We matched each inflammatory bowel disease patient by sex and date of birth (within one year) to up to five non-IBD patients within the same primary care practice. If only the month or the year was available, the date of birth was assumed to be on the 15th day of the month or on 1st July. To ensure some overlap in observation time existed for each group of matches, we picked non-IBD patients so that the index date of each inflammatory bowel disease patient (defined as the later of the date entering CPRD or date of the earliest record of an inflammatory bowel disease diagnosis) fell between the dates entering and leaving CPRD in non-IBD patients. The date entering CPRD was the later of the patient's current registration date or "up-to-standard" date of the practice, and the date leaving CPRD was the earliest of the patient's transferout date, date of death or the last data collection date of the practice.

\section{Outcome event}


The outcome event was the first record of pulmonary embolism (International Classification of Diseases, 10th revision: 126), lower limb deep vein thrombosis or other deep vein thrombosis (180 to 182) in Clinical Practice Research Datalink or Hospital Episode Statistics, verified by one of: an anticoagulant prescription within 90 days, evidence of anticoagulation on the basis of medical records within 90 days, or death from any cause within 30 days of a thromboembolic event. This definition has been validated in Clinical Practice Research Datalink.[15]

Patients were considered at risk of the outcome from the later of the index date or the date our data began. They were no longer considered at risk after the end of data or after the first instance of the outcome, whichever was earlier.

\section{At-risk periods}

We divided phases of inflammatory bowel disease activity as "acute" (or "flare"), "chronic" or "in remission". An "acute" phase began with issuance of a new corticosteroid prescription or a record of in-patient admission with Crohn's disease (International Classification of Diseases, 10th revision: K50) or ulcerative colitis (K51) as the main diagnosis following a period of remission. Patients continuing to receive corticosteroids beyond the first 120 days after a flare had started (i.e. the "acute" phase) entered a "chronic" phase, which lasted until 120 days after the last corticosteroid prescription. The remission period started 120 days after the last corticosteroid prescription or IBD-related hospital admission.[9]

Hospitalisation status was classified into "in-patient", "after discharge" and "ambulatory". The "after discharge" period lasted for six weeks following the date when a patient left hospital. Though thromboembolic events that occur sooner after 
leaving hospital are more likely to be attributable to the in-patient stay, the "after discharge" period must also be long enough so that a reasonable number of events can accrue for analysis. Our choice of six weeks was a compromise between these requirements and any length from 28 to 90 days used by other authors.

\section{Statistical analysis}

We estimated the ratio of occurrence (hazard ratios) of venous thromboembolism between inflammatory bowel disease and non-IBD patients in a Cox proportional hazards model, with adjustment for age, sex, body mass index (averaged over all the records of each patient), tobacco use, history of malignancy and previous thromboembolic events. Tobacco use was categorised as, from high to low, "current", "ex-smoker", "not current" or "unknown" based on the highest recorded level.

We further investigated the contribution of inflammatory bowel disease activity and inpatient stays to the risk of venous thromboembolism in time-varying Cox proportional hazards models, to incorporate temporal changes in inflammatory bowel disease severity and hospital use status, and in a self-controlled case series analysis, in which we used data from individuals who had a thromboembolic event and at different phases of inflammatory bowel disease activity.[19,20] We illustrated temporal changes in the cumulative hazard of thromboembolic events, in which the risk of venous thromboembolism in each period was represented by the gradient of each curve.[21]

In the self-controlled case series analysis, we examined the strength of association between an outcome, a thromboembolic event, and time-varying exposures such as different periods of hospital stays and inflammatory bowel disease activity. This 
analysis used records from patients who experienced a thromboembolic event during the observation period, and compared the probability that a thromboembolic event occurred in periods when patients were exposed (for example, during hospital stays) to unexposed (for example, while ambulatory). $[19,20]$ This approach estimates the change in the risk of venous thromboembolism in patients when their exposure status changes with time.

Analyses were carried out in Stata and in the R statistical language.[22]

\section{RESULTS}

We identified from Clinical Practice Research Datalink a cohort comprising 23,046 inflammatory bowel disease patients matched to 106,795 non-IBD patients, after excluding inflammatory bowel disease patients without any linked records from Hospital Episode Statistics $(n=33,028)$ or patients who left CPRD before their primary care practices were able to provide "up-to-standard" data ( $n=2,922)$. The large proportion of patients with no linked records from Hospital Episode Statistics was within expectation, since only half of primary care practices had consented to record linkage at the time of this study and assuming a linkage success of $80 \%$.

Among patients with a thromboembolic event, inflammatory bowel disease patients (mean $=55.0$ years, $40.2 \%$ were $41-60$ year-olds) were younger than non-IBD patients $($ mean $=59.4$ years, $43.2 \%$ were 61-80 year-olds). Inflammatory bowel disease patients also had lower body mass indices (Table 1). Patients with a thromboembolic event were also more likely to have a previous event: $20.5 \%$ had a previous thromboembolic event in inflammatory bowel disease patients, which was 
more than double the proportion in non-IBD patients (9.1\%). The proportion of patients with a history of malignancy was similar for inflammatory bowel disease (16.6\%) and non-IBD patients (14.2\%) who did not have any thromboembolic events. In patients who had a thromboembolic event, $26.5 \%$ of inflammatory bowel disease patients and $30.8 \%$ of non-IBD patients had a history of malignancy.

\section{Overall risk of a thromboembolic outcome}

The overall risk of venous thromboembolism in inflammatory bowel disease patients was $74 \%$ higher than in non-IBD patients (hazard ratio, $\mathrm{HR}=1.74,95 \% \mathrm{Cl}=1.55-$ 1.96) from Cox proportional hazards models (Table 2 and Figure 1). The risk of venous thromboembolism varied with inflammatory bowel disease activity: it rose to four times as high as in non-IBD patients $(\mathrm{HR}=4.02,95 \% \mathrm{Cl}=3.08-5.25)$ during an acute episode, and fell slightly when the inflammatory process entered the chronic phase $(\mathrm{HR}=3.71,95 \% \mathrm{Cl}=2.87-4.79)$. During remission, thromboembolism risk remained at 39\% higher than in non-IBD patients $(95 \% \mathrm{CI}=1.21-1.60)$. In inflammatory bowel disease patients, analysed using the self-controlled case series method to eliminate all time stable confounding, the thromboembolism risk during chronic phase was 2.64 times $(95 \% \mathrm{Cl}=1.76-3.96)$ the risk when in remission, which was similar to the risk of thromboembolism during the acute phase (rate ratio, $\mathrm{RR}=2.37,95 \% \mathrm{Cl}=1.71-3.29)($ Table 3 and Figure 2).

\section{During in-patient stays}

The absolute risk of venous thromboembolism during an in-patient stay (28.1 per 1,000 person-years in non-IBD and 59.5 in inflammatory bowel disease patients after major surgery; 30.3 in non-IBD and 31.1 in inflammatory bowel disease without major 
surgery) was higher than after leaving hospital (19.7 in non-IBD and 18.6 in inflammatory bowel disease after major surgery; 15.6 in non-IBD and 12.3 in inflammatory bowel disease without major surgery) and during ambulatory periods (1.1 in non-IBD and 2.0 in inflammatory bowel disease) (Table 2 and Figure 3). The risk of thromboembolism was similar between inflammatory bowel disease and nonIBD patients not undergoing any major surgery $(\mathrm{HR}=1.13,95 \% \mathrm{Cl}=0.63-2.02)$, but very few thromboembolic events occurred in each of three phases of inflammatory bowel disease activity (Table 2 and 3). In patients undergoing major surgery, the risk of thromboembolism was higher in inflammatory bowel disease patients than in nonIBD patients $(\mathrm{HR}=2.43,95 \% \mathrm{Cl}=1.20-4.92)$.

\section{Within six weeks after discharge}

The thromboembolism risk was similar between inflammatory bowel disease and non-IBD patients after major surgery $(\mathrm{HR}=1.01,95 \% \mathrm{Cl}=0.67-1.52)$ and also after admissions not involving major surgery $(\mathrm{HR}=1.03,95 \% \mathrm{Cl}=0.77-1.37)($ Table 2$)$. The risk of thromboembolism was not found to vary with inflammatory bowel disease activity after leaving hospital (Table 3 ).

\section{While ambulatory}

Inflammatory bowel disease patients were at a higher risk of venous thromboembolism than non-IBD patients while ambulatory $(\mathrm{HR}=1.71,95 \% \mathrm{Cl}=$ 1.48-1.98) (Table 2). The highest risk was during the acute phase ( $H R=3.94,95 \%$ $\mathrm{Cl}=2.79-5.57)$ and chronic phase of inflammatory bowel disease activity $(\mathrm{HR}=$ $3.97,95 \% \mathrm{Cl}=2.90-5.45)$. The risk of thromboembolism fell during remission, but remained at 38\% higher than non-IBD patients $(95 \% \mathrm{Cl}=1.17-1.63)$. Among 
inflammatory bowel disease patients, thromboembolism risk was higher than in remission during both acute phase $(\mathrm{RR}=2.64,95 \% \mathrm{Cl}=1.76-3.95)$ and chronic phase of inflammatory bowel disease activity $(R R=3.05,95 \% \mathrm{Cl}=1.94-4.80)($ Table 3).

\section{DISCUSSION}

We have demonstrated inflammatory bowel disease patients were at a higher risk of venous thromboembolism $-74 \%$ greater than non-IBD patients (overall adjusted HR $=1.74,95 \% \mathrm{Cl}=1.55-1.96)$. Consistent with our previous study, thromboembolism risk was found to be raised when inflammatory bowel disease was active and remained so while ambulant, and the period of elevated risk not confined only to inpatient episodes.[9] We have also shown the risk of thromboembolic events was higher during in-patient episodes involving major surgery, which persisted for a number of weeks after leaving hospital.

\section{Strengths and weaknesses}

This study has strengths and weaknesses inherent to the use of routinely collected data. By using anonymised data, we have forfeited the ability to verify the accuracy of individual patient's clinical records. This is not a major drawback since the exposure status (inflammatory bowel disease) central to our study and its outcome (venous thromboembolism) have been demonstrated to be reliably recorded in the data we used.[15,16] The data we used are incomplete in some variables, and for example, completeness of data on body mass index and tobacco use (around 15\% and $5 \%$ with unknown status) cannot be improved further and self-reported tobacco use 
history cannot be verified because of anonymisation. This misclassification and residual confounding may lead to biased estimation of their effects on the risk of thromboembolic events. We have repeated our analyses, but without adjustment for these variables, and found the estimated effects were similar to those presented. This implied tobacco use and body mass index did not have a role in determining thromboembolism risk which was as important as one may expect. Additionally, we have used the self-controlled case series method to remove any confounding effect of variables whose values were stable within the observation period (eg. tobacco use and body mass index), and results from this method were consistent with those from the Cox proportional hazards models.

Ascertainment error may have affected our assessment of disease activity similarly. Since acute inflammatory bowel disease episodes were defined based on corticosteroid prescriptions, we could have omitted milder exacerbations that were managed by increasing the dosage of aminosalicylates, and potentially, courses of corticosteroids prescribed exclusively in secondary care. We attempted to avoid the latter situation by accepting hospital admission for inflammatory bowel disease as evidence of an acute episode. This means our results reflect only inflammatory activity that was severe enough to require corticosteroids or a hospital stay, and misclassification would inevitably be present. Misclassification error was unlikely to be differential between patients with and without an thromboembolic event, and we would therefore not expect a bias other than a reduction in the estimated effects. We have no access to hospital prescription records, and thus unable to determine whether in-patient thromboprophylaxis was given. Since routine thromboprophylaxis is recommended in the national guidelines, we have assumed that it was offered universally. Hence our estimated effects represented the in-patient risk of 
thromboembolism despite prophylaxis. Until access to linked in-patient prescriptions becomes possible, this remain unfortunately unproven.

Use of routinely collected data of such size and richness of data items has allowed sufficient subdivision of observation time to meet our aims and to provide reliable data on many potential confounders of the relationship we examined. Since exposures and outcomes are recorded independently for reasons unconnected to our research, there is limited opportunity for information bias. Selection bias should also not be a problem because we have selected inflammatory bowel disease patients and their controls based only on their inflammatory bowel disease diagnosis and demographics from population-based data. Since Clinical Practice Research Datalink is representative of the UK population, our results should therefore be generalisable to that population, and arguably to other similar populations.[14]

\section{Our findings in the context of existing knowledge}

It is generally recognised that inflammatory bowel disease patients are at an increased risk of thromboembolic events - between 1.5- and 3.5-fold increase overall.[2,3] Our estimates are in line with this, and likewise, our finding that the risk of venous thromboembolism is connected to inflammatory bowel disease activity accords with our previous study and with another study showing many IBD-related thromboembolic events occur in periods of intense disease activity. $[9,23]$ We used corticosteroid prescription as a proxy for disease activity, and other studies have suggested a more direct role for corticosteroids. [24] Our estimation of thromboembolism risk in ambulatory patients with active inflammatory bowel disease is lower than in our previous study, perhaps suggesting bias from previous 
misclassification of at-risk periods. [9] We estimated hospital admission and discharge dates from general practice records previously, whereas we had accurate information from hospital data in this study. It may be possible that in-patient periods in our previous study were more likely to be misclassified as ambulant in periods of active or chronic inflammatory bowel disease activity than in remission, leading to biased estimation of the risk of thromboembolism in ambulatory periods. This may also explain why, contrary to the results from our previous study, the risks of thromboembolism in acute and chronic phases of inflammatory bowel disease appeared to be similar.

New findings from this study include the effect of surgery on the risk of venous thromboembolism and the prolonged at-risk period after leaving hospital. We are by no means the first to recognise patients undergoing surgery are at a greater risk of thromboembolic events among inflammatory bowel disease or non-IBD patients. Surgery has long been recognised as a risk factor irrespective of inflammatory bowel disease.[25] More specific data on surgery in inflammatory bowel disease patients are also available - the odds of thromboembolism associated with elective colectomy were 3.7 times and with emergency colectomy 5.3 times that in ulcerative colitis patients receiving medical therapy alone.[26] It is therefore unsurprising that inflammatory bowel disease patients undergoing major surgery had some of the highest thromboembolism risk during in-patient episodes and after leaving hospital. However, our findings on the effect of surgery on venous thromboembolism after leaving hospital are not entirely consistent with the recent literature. Surgical admission is not related to the risk of thromboembolic events after correcting for confounding factors in a recent case-control study that has included in-patient thromboprophylaxis data.[27] We have no access to data on in-patient prescription 
and are thus unable to exclude the possible effect of thromboprophylaxis. However since in-patient thromboprophylaxis is part of the standard care in both IBD-related surgical and non-surgical admissions, the differences we have found are unlikely to be attributable to this practice.[28] Thus, our finding of high risk of venous thromboembolism in the first six weeks after leaving hospital following surgery for inflammatory bowel disease is valid notwithstanding this limitation of our data.

\section{Prophylaxis against venous thromboembolism}

Our aim was to estimate, more accurately, the absolute risk of venous thromboembolism in different phases of inflammatory bowel disease activity, with a view to better support decision-making of when thromboprophylaxis is likely to be appropriate. The risk of thromboembolic events increases to 1.5-3 times the background risk after air travel in the general population, 3-5 times during pregnancy and puerperium and 4-7 times in persons taking oral contraceptives.[29] The 4-fold increase in thromboembolism risk associated with acute or chronic inflammatory bowel disease activity while ambulatory (4.9 per 1,000 person-years) would therefore not be a sufficient reason for routine prophylaxis against venous thromboembolism among inflammatory bowel disease patients.

The risk of thromboembolism is substantially higher in both inflammatory bowel disease and non-IBD patients while in hospital, especially after major surgery (close to 30 per 1,000 person-years). The current consensus is to offer prophylaxis to inhospital inflammatory bowel disease patients until they are ambulant, and it is important to recognise much of the risk has been reduced by such prophylaxis. [4,3032] 
In recent years there has been a growing body of evidence on the persistence of the risk of thromboembolism after leaving hospital for major surgery and the potential for a longer period of prophylaxis. Extension of thromboprophylaxis has been shown to be safe and efficacious, especially after surgery for colorectal cancer.[33-35] This has become routine practice and is now recommended in national guidelines. [13] We have found that the risk of a thromboembolic event persists after surgery in inflammatory bowel disease patients for some time after leaving hospital. This is also supported by another study showing an excess risk of venous thromboembolism in those undergoing emergency surgery.[36] The size of the risk of thromboembolism we found is consistent with other patients after major surgery, suggesting similar post-operative risks in inflammatory bowel disease patients and in patients undergoing surgery for colorectal cancer.[36-38]

\section{Conclusions}

We found inflammatory bowel disease patients have a 1.75-fold increase in the risk of thromboembolism overall, and that the absolute risk is highest during hospital admissions especially after surgery. We have confirmed patients outside hospital have a higher risk when their inflammatory bowel disease is active, but the size of the absolute risk does not warrant routine thromboprophylaxis. We have also shown that inflammatory bowel disease patients remain at high risk of thromboembolic events after leaving hospital for surgery, and their absolute risk is similar to other patients undergoing major surgery. Our findings suggest that the current focus on thromboprophylaxis in hospitalised inflammatory bowel disease patients is appropriate, but raises the question on whether it should be extended to the period 
after leaving hospital for inflammatory bowel disease patients as it is for colorectal cancer patients. 


\section{Contributions}

All authors searched the literature, designed the study, interpreted the findings and revised the manuscript. Thomas Chu carried out data management, statistical analysis and drafted the manuscript. Tim Card helped with cohort identification and data management. Matthew Grainge helped with statistical analysis.

\section{Conflict of Interest}

None of the authors have any conflict of interest.

This study was fully funded by Crohn's and Colitis UK (reference number M10-1). Crohn's and Colitis UK does not have any involvement in study design; in data collection, analysis and interpretation of findings; in the writing of the report; and in the decision to submit the article for publication.

\section{References}

1 Edwards FC, Truelove SC. The Course and Prognosis of Ulcerative Colitis. III. Complications. Gut 1964;5:1-22. doi:10.1136/gut.5.1.1

2 Murthy SK, Nguyen GC. Venous thromboembolism in inflammatory bowel disease: an epidemiological review. Am J Gastroenterol 2011;106:713-8. doi:10.1038/ajg.2011.53

3 Yuhara $\mathrm{H}$, Steinmaus $\mathrm{C}$, Corley D, et al. Meta-analysis: The risk of venous thromboembolism in patients with inflammatory bowel disease. Aliment Pharmacol Ther 2013;37:953-62. doi:10.1111/apt.12294 
4 Qaseem A, Chou R, Humphrey LL, et al. Venous thromboembolism prophylaxis in hospitalized patients: A clinical practice guideline from the American College of Physicians. Ann Intern Med 2011;155:625-32.

doi:10.7326/0003-4819-155-9-201111010-00011

5 Nguyen GC, Bernstein CN, Bitton A, et al. Consensus statements on the risk, prevention, and treatment of venous thromboembolism in inflammatory bowel disease: Canadian association of gastroenterology. Gastroenterology 2014;146. doi:10.1053/j.gastro.2014.01.042

6 Harbord M, Eliakim R, Bettenworth D, et al. Third European evidence-based consensus on diagnosis and management of ulcerative colitis. Part 2: Current management. J Crohn's Colitis 2017;11:769-84. doi:10.1093/eccojcc/jjx009

7 Gionchetti P, Dignass A, Danese S, et al. 3rd European evidence-based consensus on the diagnosis and management of Crohn's disease 2016: Part 2: Surgical management and special situations. J Crohn's Colitis 2017;11:135-49. doi:10.1093/ecco-jcc/jjw169

8 Pleet JL, Vaughn BP, Morris JA, et al. The use of pharmacological prophylaxis against venous thromboembolism in hospitalised patients with severe active ulcerative colitis. Aliment Pharmacol Ther 2014;39:940-8. doi:10.1111/apt.12691

9 Grainge MJ, West J, Card TR. Venous thromboembolism during active disease and remission in inflammatory bowel disease: a cohort study. Lancet 2010;375:657-63. doi:10.1016/S0140-6736(09)61963-2 
Abdul Sultan A, Tata LJ, Grainge MJ, et al. The Incidence of First Venous Thromboembolism in and around Pregnancy Using Linked Primary and Secondary Care Data: A Population Based Cohort Study from England and Comparative Meta-Analysis. PLoS One 2013;8.

doi:10.1371/journal.pone.0070310

11 Blom JW, Vanderschoot JPM, Oostindiër MJ, et al. Incidence of venous thrombosis in a large cohort of 66329 cancer patients: Results of a record linkage study. J Thromb Haemost 2006;4:529-35. doi:10.1111/j.15387836.2006.01804.x

12 Ramagopalan S V, Wotton CJ, Handel AE, et al. Risk of venous thromboembolism in people admitted to hospital with selected immunemediated diseases: record-linkage study. BMC Med 2011;9:1. doi:10.1186/1741-7015-9-1

13 National Clinical Guideline Centre - Acute and Chronic Conditions. Venous thromboembolism: reducing the risk of venous thromboembolism (deep vein thrombosis and pulmonary embolism) in patients admitted to hospital. London, UK: 2010. https://www.nice.org.uk/guidance/cg92

14 Herrett E, Gallagher AM, Bhaskaran K, et al. Data Resource Profile: Clinical Practice Research Datalink (CPRD). Int J Epidemiol 2015;44:827-36. doi:10.1093/ije/dyv098

15 Lawrenson R, Todd JC, Leydon GM, et al. Validation of the diagnosis of venous thromboembolism in general practice database studies. Br J Clin Pharmacol 2000;49:591-6. doi:10.1046/j.1365-2125.2000.00199.x 
16 Lewis JD, Brensinger C, Bilker WB, et al. Validity and completeness of the General Practice Research Database for studies of inflammatory bowel disease. Pharmacoepidemiol Drug Saf 2002;11:211-8. doi:10.1002/pds.698

17 Herbert A, Wijlaars L, Zylbersztejn A, et al. Data Resource Profile: Hospital Episode Statistics Admitted Patient Care (HES APC). Int J Epidemiol 2017;46:1093-1093i. doi:10.1093/ije/dyx015

$18 \quad$ NHS Digital. The processing cycle and HES data quality. 2017.

http://content.digital.nhs.uk/article/1825/The-processing-cycle-and-HES-dataquality (accessed 31 Dec 2017).

19 Whitaker HJ, Farrington CP, Spiessens B, et al. Tutorial in biostatistics: The self-controlled case series method. Stat Med 2006;25:1768-97. doi:10.1002/ $\operatorname{sim} .2302$

20 Whitaker HJ, Hocine MN, Farrington CP. The methodology of self-controlled case series studies. Stat Methods Med Res 2009;18:7-26.

doi:10.1177/0962280208092342

21 Therneau TM, Grambsch PM. Modeling Survival Data: Extending the Cox Model. New York, USA: : Springer Science+Business Media 2000. doi:10.1007/978-1-4757-3294-8

22 R Core Team. R: A Language and Environment for Statistical Computing. 2017. https://www.r-project.org

23 Papay $\mathrm{P}$, Miehsler W, Tilg $\mathrm{H}$, et al. Clinical presentation of venous thromboembolism in inflammatory bowel disease. J Crohn's Colitis 2013;7:723-9. doi:10.1016/j.crohns.2012.10.008 
24 Higgins PDR, Skup M, Mulani PM, et al. Increased risk of venous thromboembolic events with corticosteroid vs biologic therapy for inflammatory bowel disease. Clin Gastroenterol Hepatol 2015;13:316-21. doi:10.1016/j.cgh.2014.07.017

25 Wheeler HB, Anderson FA. Diagnostic approaches for deep vein thrombosis. Chest 1986;89. doi:10.1378/chest.89.5_Supplement.407S

26 Kaplan GG, Lim A, Seow CH, et al. Colectomy is a risk factor for venous thromboembolism in ulcerative colitis. World J Gastroenterol 2015;21:125160. doi:10.3748/wjg.v21.i4.1251

27 Ananthakrishnan AN, Cagan A, Gainer VS, et al. Thromboprophylaxis Is Associated With Reduced Post-hospitalization Venous Thromboembolic Events in Patients With Inflammatory Bowel Diseases. Clin Gastroenterol Hepatol 2014;12:1905-10. doi:10.1016/j.cgh.2014.02.034

28 Chen J-H, Andrews JM, Kariyawasam V, et al. Review article: acute severe ulcerative colitis - evidence-based consensus statements. Aliment Pharmacol Ther 2016;44:127-44. doi:10.1111/apt.13670

29 Card T, Chu T. IBD and venous thromboembolism: A review. Inflamm Bowel Dis Monit 2012;13:58-64. http://www.remedicajournals.com/InflammatoryBowel-Disease-Monitor/Browselssues/Volume-13-Issue-2/Article-IBD-andVenous-Thromboembolism-A-Review

30 Geerts WH, Bergqvist D, Pineo GF, et al. Prevention of venous thromboembolism: American College of Chest Physicians evidence-based clinical practice guidelines (8th edition). Chest 2008;133. doi:10.1378/chest.08-0656 
31 Kornbluth A, Sachar DB. Ulcerative colitis practice guidelines in adults (update): American College of Gastroenterology, Practice Parameters Committee. Am J Gastroenterol 2004;99:1371-85. doi:10.1111/j.15720241.2004.40036.x

32 Mowat, Cole, Windsor, et al. Guidelines for the management of inflammatory bowel disease in adults. Gut 2011;60:571-607. doi:10.1136/gut.2010.224154

33 Lausen I, Jensen R, Jorgensen LN, et al. Incidence and prevention of deep venous thrombosis occurring late after general surgery: Randomised controlled study of prolonged thromboprophylaxis. Eur J Surg 1998;164:65763. doi:10.1080/110241598750005534

34 Rasmussen MS, Jorgensen LN, Wille-Jørgensen P, et al. Prolonged prophylaxis with dalteparin to prevent late thromboembolic complications in patients undergoing major abdominal surgery: a multicenter randomized open-label study. J Thromb Haemost 2006;4:2384-90. doi:10.1111/j.15387836.2006.02153.x

35 Rasmussen MS, Jørgensen LN, Wille-Jørgensen P. Prolonged thromboprophylaxis with Low Molecular Weight heparin for abdominal or pelvic surgery. Cochrane Database Syst Rev: 2009.

doi:10.1002/14651858.CD004318.pub2

36 El-Dhuwaib Y, Selvasekar C, Corless DJ, et al. Venous thromboembolism following colorectal resection. Color Dis 2017;19:385-94. doi:10.1111/codi.13529 
37 Moghadamyeghaneh Z, Alizadeh RF, Hanna MH, et al. Post-hospital discharge venous thromboembolism in colorectal surgery. World J Surg 2016;40:1255-63. doi:10.1007/s00268-015-3361-5

38 Wilson MZ, Connelly TM, Tinsley A, et al. Ulcerative colitis is associated with an increased risk of venous thromboembolism in the postoperative period:

The results of a matched cohort analysis. Ann Surg 2015;261:1160-6.

doi:10.1097/SLA.0000000000000788 


\section{Tables}

Table 1: Distribution of patient demographics, by inflammatory bowel disease (IBD) and venous thromboembolism (VTE) status. 


\begin{tabular}{|c|c|c|c|c|c|c|c|c|}
\hline \multirow[b]{4}{*}{ Total } & \multicolumn{4}{|c|}{ No VTE $(\mathrm{N}=128,346)$} & \multicolumn{4}{|c|}{ Developed VTE $(\mathrm{N}=1,495)$} \\
\hline & \multicolumn{2}{|c|}{$\begin{array}{l}\text { Non-IBD } \\
\text { patients }\end{array}$} & \multicolumn{2}{|c|}{ IBD patients } & \multicolumn{2}{|c|}{$\begin{array}{l}\text { Non-IBD } \\
\text { patients }\end{array}$} & \multicolumn{2}{|c|}{ IBD patients } \\
\hline & $\mathbf{n}$ & $\%$ & $\mathbf{n}$ & $\%$ & $\mathbf{n}$ & $\%$ & $\mathbf{n}$ & $\%$ \\
\hline & 105,730 & & 22,616 & & 1,065 & & 430 & \\
\hline Male & 49,879 & 47.2 & 10,620 & 47.0 & 469 & 44.0 & 198 & 46.0 \\
\hline $\begin{array}{l}\text { Mean age } \\
\text { (years) }\end{array}$ & 48.0 & & 48. & & 59.4 & & 55.0 & \\
\hline \multicolumn{9}{|l|}{$\begin{array}{l}\text { Age group } \\
\text { (years) }\end{array}$} \\
\hline $0-20$ & 5,000 & 4.7 & 1,041 & 4.6 & 7 & 0.7 & 5 & 1.2 \\
\hline $21-40$ & 34,714 & 32.8 & 7,518 & 33.2 & 130 & 12.2 & 79 & 18.4 \\
\hline $41-60$ & 36,482 & 34.5 & 7,718 & 34.1 & 379 & 35.6 & 173 & 40.2 \\
\hline $61-80$ & 24,234 & 22.9 & 5,153 & 22.8 & 460 & 43.2 & 148 & 34.4 \\
\hline over 80 & 5,300 & 5.0 & 1,186 & 5.2 & 89 & 8.4 & 25 & 5.8 \\
\hline History of VTE & 1,634 & 1.5 & 589 & 2.6 & 97 & 9.1 & 88 & 20.5 \\
\hline $\begin{array}{l}\text { History of } \\
\text { cancer }\end{array}$ & 15,012 & 14.2 & 3,745 & 16.6 & 328 & 30.8 & 114 & 26.5 \\
\hline \multicolumn{9}{|l|}{$\begin{array}{l}\text { Body mass } \\
\text { index }\end{array}$} \\
\hline $0-18.5$ & 2,693 & 2.5 & 808 & 3.6 & 14 & 1.3 & 7 & 1.6 \\
\hline $18.5-25.0$ & 39,013 & 36.9 & 9,422 & 41.7 & 281 & 26.4 & 135 & 31.4 \\
\hline $25.0-30.0$ & 29,930 & 28.3 & 6,470 & 28.6 & 360 & 33.8 & 147 & 34.2 \\
\hline $30.0-50.0$ & 15,697 & 14.8 & 3,060 & 13.5 & 294 & 27.6 & 95 & 22.1 \\
\hline Unknown & 18,397 & 17.4 & 2,856 & 12.6 & 116 & 10.9 & 46 & 10.7 \\
\hline \multicolumn{9}{|l|}{ Tobacco use } \\
\hline Non-current & 49,280 & 46.6 & 10,456 & 46.2 & 482 & 45.3 & 184 & 42.8 \\
\hline Current & 32,704 & 30.9 & 6,574 & 29.1 & 316 & 29.7 & 110 & 25.6 \\
\hline Ex-smoker & 16,240 & 15.4 & 4,726 & 20.9 & 237 & 22.3 & 124 & 28.8 \\
\hline Unknown & 7,506 & 7.1 & 860 & 3.8 & 30 & 2.8 & 12 & 2.8 \\
\hline
\end{tabular}


Table 2: Estimated hazard ratios, from time-varying Cox models, of the risk of a venous thromboembolic event (VTE) at different periods of inflammatory bowel disease (IBD) activity and hospitalisation, when compared to non-IBD patients in identical situations.

Hazard ratios were adjusted for age, sex, body mass index, tobacco use, history of cancer and history of venous thromboembolism.

$\mathrm{Cl}=$ confidence interval, $\mathrm{p}-\mathrm{y}=$ person-years. 


\begin{tabular}{|c|c|c|c|c|c|}
\hline & VTE events & $\begin{array}{l}\text { Follow-up } \\
\text { (person-years) }\end{array}$ & $\begin{array}{l}\text { Incidence } \\
\text { rate } \\
(1,000 p-y)\end{array}$ & $\begin{array}{l}\text { Hazard ratio } \\
\text { (adjusted) }\end{array}$ & $95 \% \mathrm{Cl}$ \\
\hline \multicolumn{6}{|c|}{ All periods combined } \\
\hline Non-IBD patients & 970 & $630,041.2$ & 1.5 & 1.00 & \\
\hline IBD patients & 383 & $135,972.4$ & 2.8 & 1.74 & $1.55-1.96$ \\
\hline Acute & 58 & $9,763.7$ & 5.9 & 4.02 & $3.08-5.25$ \\
\hline Chronic & 63 & $9,763.5$ & 6.5 & 3.71 & $2.87-4.79$ \\
\hline Remission & 262 & $116,445.3$ & 2.2 & 1.39 & $1.21-1.60$ \\
\hline \multicolumn{6}{|c|}{ Inpatient, no major surgery } \\
\hline Non-IBD patients & 40 & $1,318.9$ & 30.3 & 1.00 & \\
\hline IBD patients & 16 & 513.9 & 31.1 & 1.13 & $0.63-2.02$ \\
\hline Acute & 3 & 87.2 & 34.4 & 1.66 & $0.51-5.36$ \\
\hline Chronic & 4 & 78.5 & 51.0 & 1.93 & $0.69-5.41$ \\
\hline Remission & 9 & 348.3 & 25.8 & 0.88 & $0.43-1.81$ \\
\hline \multicolumn{6}{|c|}{ Inpatient, had major surgery } \\
\hline Non-IBD patients & 15 & 533.0 & 28.1 & 1.00 & \\
\hline IBD patients & 16 & 268.7 & 59.5 & 2.43 & $1.20-4.92$ \\
\hline Acute & 3 & 55.6 & 53.9 & 3.26 & $0.94-11.29$ \\
\hline Chronic & 1 & 44.5 & 22.5 & 1.06 & $0.14-8.02$ \\
\hline Remission & 12 & 168.6 & 71.2 & 2.55 & $1.19-5.44$ \\
\hline \multicolumn{6}{|c|}{ Within 6 weeks after discharge, no major surgery } \\
\hline Non-IBD patients & 145 & $5 \quad 9,323.7$ & 15.6 & 1.00 & \\
\hline IBD patients & 70 & $5,676.0$ & 12.3 & 1.03 & $0.77-1.37$ \\
\hline Acute & 15 & $1,314.8$ & 11.4 & 1.12 & $0.66-1.91$ \\
\hline Chronic & 12 & $1,041.8$ & 11.5 & 1.08 & $0.60-1.95$ \\
\hline Remission & 43 & $3,319.3$ & 13.0 & 0.98 & $0.70-1.39$ \\
\hline \multicolumn{6}{|c|}{ Within 6 weeks after discharge, had major surgery } \\
\hline Non-IBD patients & 97 & $7 \quad 4,912.2$ & 19.7 & 1.00 & \\
\hline IBD patients & 31 & $1,666.8$ & 18.6 & 1.01 & $0.67-1.52$ \\
\hline Acute & 3 & 199.4 & 15.0 & 1.00 & $0.32-3.15$ \\
\hline Chronic & 5 & 179.0 & 27.9 & 1.62 & $0.66-3.99$ \\
\hline Remission & 23 & $1,288.5$ & 17.9 & 0.94 & $0.59-1.48$ \\
\hline \multicolumn{6}{|l|}{ Ambulatory } \\
\hline Non-IBD patients & 673 & $613,953.4$ & 1.1 & 1.00 & \\
\hline IBD patients & 250 & $127,847.1$ & 2.0 & 1.71 & $1.48-1.98$ \\
\hline Acute & 34 & $8,106.6$ & 4.2 & 3.94 & $2.79-5.57$ \\
\hline Chronic & 41 & $8,419.8$ & 4.9 & 3.97 & $2.90-5.45$ \\
\hline Remission & 175 & $111,320.6$ & 1.6 & 1.38 & $1.17-1.63$ \\
\hline
\end{tabular}


Table 3: Estimated incidence rate ratios, from self-controlled case series analysis, of the risk of a venous thromboembolic event (VTE) at different periods of inflammatory bowel disease activity, in different periods of hospitalisation.

$\mathrm{Cl}=$ confidence interval . 


\begin{tabular}{|c|c|c|c|}
\hline & $\begin{array}{c}\text { VTE } \\
\text { events }\end{array}$ & Rate ratio & $95 \% \mathrm{Cl}$ \\
\hline \multicolumn{4}{|l|}{ All periods combined } \\
\hline Remission & 1,233 & 1.00 & \\
\hline Acute & 58 & 2.37 & $1.71-3.29$ \\
\hline Chronic & 63 & 2.64 & $1.76-3.96$ \\
\hline \multicolumn{4}{|c|}{ Inpatient, no major surgery } \\
\hline Remission & 49 & 1.00 & \\
\hline Acute & 3 & 1.13 & $0.33-3.93$ \\
\hline Chronic & 4 & 1.96 & $0.64-5.98$ \\
\hline \multicolumn{4}{|c|}{ Inpatient, had major surgery } \\
\hline Remission & 27 & 1.00 & \\
\hline Acute & 3 & 1.03 & $0.28-3.77$ \\
\hline Chronic & 1 & 0.68 & $0.09-5.33$ \\
\hline \multicolumn{4}{|c|}{ Within 6 weeks after discharge, no major surgery } \\
\hline Remission & 188 & 1.00 & \\
\hline Acute & 15 & 0.97 & $0.55-1.72$ \\
\hline Chronic & 12 & 1.01 & $0.51-2.01$ \\
\hline \multicolumn{4}{|c|}{ Within 6 weeks after discharge, had major surgery } \\
\hline Remission & 120 & 1.00 & \\
\hline Acute & 3 & 0.64 & $0.19-2.13$ \\
\hline Chronic & 5 & 1.45 & $0.54-3.88$ \\
\hline \multicolumn{4}{|l|}{ Ambulatory } \\
\hline Remission & 849 & 1.00 & \\
\hline Acute & 34 & 2.64 & $1.76-3.95$ \\
\hline Chronic & 41 & 3.05 & $1.94-4.80$ \\
\hline
\end{tabular}




\section{Figure legends}

Figure 1: Cumulative hazard curves of venous thromboembolic events among inflammatory bowel disease patients (broken line) and non-IBD patients (solid line) in the entire observation time.

The gradient of each line represents the risk of venous thromboembolism.

Figure 2 left: Cumulative hazard curves of venous thromboembolic events from the beginning of different time periods in non-IBD patients (black) and inflammatory bowel disease patients: acute phase inflammatory bowel disease (red), chronic (purple), in remission (blue).

Figure 2 right: Same as Figure 2 left, focusing on events occurring up to 180 days from the beginning of each time period.

Figure 3 left: Cumulative hazard curves of venous thromboembolic events up to 180 days from the beginning of different time periods in inflammatory bowel disease patients: ambulatory (black), in-patient stays (red) and within six weeks after leaving hospital (purple), after major surgery (broken lines) or without undergoing major surgery (solid lines).

Figure 3 right: Same as Figure 3 left, focusing on events occurring up to 42 days from the beginning of each time period. 